\title{
Structural Damage Identification of Pipe Based on GA and SCE-UA Algorithm
}

\author{
Yaojin Bao, ${ }^{1}$ He Xia, ${ }^{1}$ Zhenming Bao, ${ }^{2}$ Shuiping $\mathrm{Ke}^{3}$ and Yahui $\mathrm{Li}^{4}$ \\ ${ }^{1}$ College of Civil Engineering, Beijing Jiaotong University, Beijing 100044, China \\ ${ }^{2}$ School of Naval Architecture Engineering, Dalian University of Technology, Dalian 116024, China \\ ${ }^{3}$ College of Management and Economics, Tianjin University, Tianjin 300072, China \\ ${ }^{4}$ Transportation Management College, Dalian Maritime University, Dalian 116026, China
}

Correspondence should be addressed to Shuiping Ke; ksppp2003@163.com

Received 1 November 2013; Revised 8 November 2013; Accepted 10 November 2013

Academic Editor: Bin Yu

Copyright (C) 2013 Yaojin Bao et al. This is an open access article distributed under the Creative Commons Attribution License, which permits unrestricted use, distribution, and reproduction in any medium, provided the original work is properly cited.

\begin{abstract}
Structure of offshore platform is very huge, which is easy to be with crack caused by a variety of environmental factors including winds, waves, and ice and threatened by some unexpected factors such as earthquake, typhoon, tsunami, and ship collision. Thus, as a main part of the jacket offshore platform, pipe is often with crack. However, it is difficult to detect the crack due to its unknown location. Genetic algorithm (GA) and SCE-UA algorithm are used to detect crack in this paper, respectively. In the experiment, five damages of the pipe in the platform model can be intelligently identified by genetic algorithm (GA) and SCE-UA. The network inputs are the differences between the strain mode shapes. The results of the two algorithms for structural damage diagnosis show that both of the two algorithms have high identification accuracy and good adaptability. Furthermore, the error of SCE-UA algorithm is smaller. The results also suggest that the structural damage of pipe can be identified by intelligent algorithm.
\end{abstract}

\section{Introduction}

Nondestructive testing of fault diagnosis can detect whether the construction has flaws under the condition that the construction is not assembled and destroyed, because of properties of material changing with the flaws. General nondestructive testing such as impact-echo method, infrared method, and ultrasonic method is all local damage detection technology that need check damaged points of the constructions first. Although these technologies do not need many instruments and their consequences are accurate, they spend long time and high cost to detect structural damage. In addition, they are hard to detect and evaluate some invisible components about some large-scale complicated structures completely and accurately. Heuristic algorithm is often a first choice to solve complicated problem [1-4]. Thus, this paper attempts to identify the structural damage for pipe with intelligent algorithm.

One of the most important problems of damage identification is to determine damage signature. The damage index of strain is more sensitive than the displacement damage index; therefore, the application fields of strain modal are more widely. Hillary and Ewins [5] proposed the concept of strain modal and applied the strain transfer function to the identification of exciting force. Staker [6] utilized the strain transfer function to estimate the fatigue lifetime. Bernasconi and Ewins [7] and Yam et al. [8] deduced and discussed the theory of strain modal by using displacement modal differential operation method. Tsang [9] used element format to verify the correlation theory of strain modal that was verified by numerical simulation and experiment. Hong et al. [10] used the property of Wavelet Transform which could forecast the Lipshitz index and combined the Wavelet Transform with Lipshitz index to estimate damage. Ren et al. [11] applied Wavelet Transform and Lipshitz index to locate the damage and identify the degree of the damage under the moving load. Kirkegaard and Rytter [12] took advantage of the frequency change before and after damage, applying BP neural networks to locate and identify the damage of steel beam. Mitsuru et al. [13] took relative displacement and relative speed between structure layers as input of the whole network and took the recovery ability between layers as output, using the steel 
structure data of seven layers before and after repair to verify the effectiveness of the proposed method. Ruotolo and Surace [14] put BP neural networks into use to diagnose the damage of slab construction. Masri et al. [15] proved that BP neural network is a powerful tool to dissolve the typical structural dynamic system identification problem. Chiang and Lai [16] did relative researches about construe damage identification using GA: first, approximate location of a structural damage is estimated by using modal residual force; then, the possibility of non unique recognition results will be reduced by using GA; at last, possible damage location will be determined by using optimization method. Chou and Ghaboussi [17] regarded a damage problem as an optimization problem and adopted GA to solve it. Cross-sectional area and change of structure modulus of elasticity could be estimated by measuring the freedom to the static displacement. Different from other algorithms, GA confirms the optimum value of objective function by searching a lot of points. It is found that GA can identify the structural damage even with little information. Yi and Liu [18] employed the weighted combination of vibration mode errors and frequency errors to do some numerical simulation about damage of fixed beam, fivespan continuous beams, and three spans ten layer framework. They considered that global search ability of GA is useful to identify the structural damage. Zhu and Xiao [19] defined the relative error summation of stress test and stress analysis of all point in the structure as objective function and imposed inequality constraint condition and penalty function. They identified the damage of the Zhaobaoshan bridge.

The effectiveness of construal damage identification based on GA dependeds on the stability of the objective function and algorithm. Considering that GA can perform optimization search based on multiparameter, the objective function based on multiple information can enhance the accuracy of damage identification on some degree. This paper adopted the intelligent algorithm based on strain modal to identify the damage of the nonpenetrative platform pipe crack. Selecting five damages of the platform as an example, this paper used GA and SCE-UA algorithm with better parallel effect to obtain the signal damage degree output of the platform model. At the same time, two methods were evaluated by using the same data.

\section{Improved GA for Pipe Structure Damage Identification}

2.1. Coarse-Grained Strategies. GA has disadvantages such as precocity and low search efficiency in a practical application. Therefore, the eventual result is local optimal solution, not global optimal solution. For this reason, this paper drew upon predecessors and introduced genetic algorithm to prevent the breeding between relatives. Coarse-grain genetic algorithm is also known as MIMD or distributed genetic algorithm. Individuals are exchanged between the islands, which is called the migration. The division of population and the migration strategy are the pivotal issues of the coarse-grain genetic algorithm.

If the terminal conditions are the same, serial genetic algorithm and coarse-grain genetic algorithm have different iteration time and number of times. That is because that the genetic operators of serial genetic algorithm are operated in the local environment. At present, coarse-grain genetic algorithm has some difficulties, the most important one of which is how to determine the right migration policies.

\subsection{Parallel Strategy}

Step 1 (Migration Operation). To improve the path diversity, new paths need to be exploited so that better solutions could be obtained. Thus, migration operation is introduced, which means that some excellent individuals are migrated to other subgroups in search of more optimal paths [20]. When external individuals immigrated into a stable new local environment, some individual of the original subgroup will be stimulated by the environment and make the leap of progress, which is very similar to nature.

Step 2 (Convergence Judgment). If the operation reaches the maximum number of iterations or satisfies the convergence condition, then exit sub. Otherwise go to Step 2. The specific flow chart is as in Figure 1.

\subsection{GA Parameters Determination for Damage Identification}

(1) Design Variable. The damage degree of cell $\alpha_{i}$ ( $i$ is on behalf of cell number) is treated as design variable. If $\alpha_{i}=0$, this cell has no damage. The number of design variable should be equal to the number of possible damage cells.

(2) Fitness Function. Due to the fact that it is a minimization problem, GA does the selective operation according to individual fitness value. The bigger the fitness value is, the greater the probability chosen into the next generation was. Therefore, a fitness function should be used to transform the individual objective function values. After transforming, the fitness value will be larger if the objective function value is smaller. The fitness function is as follows:

$$
\text { fitness }=\frac{1}{1+\sum_{i=1}^{N} \sum_{j=1}^{M}\left|u_{i j}^{m}-u_{i j}^{a}\right|} .
$$

(3) Genetic Manipulation. This example uses real coding to describe the individuals, and the value of genes of chromosome is viewed as the damage degree of corresponding cell. Assume that there is a line with a certain length; each parent corresponds to the part of the line according to the fitness value with the ratio. The algorithm moves along the line in the same size of the step. Every step of the algorithm determines the location of the parent based on landing position, and the value of the first step is uniform random value of a less step. Then, mutation and crossover operation should be fulfilled by creating a new binary vector. If one digit of the vector is 1 , the gene comes from the first generation, and if it is 0 , the gene is generated by the second generation and these genes should be merged to form a new individual.

(4) Parallel Strategies. First, the individual similarity of the current population ought to be calculated. It is shown that 


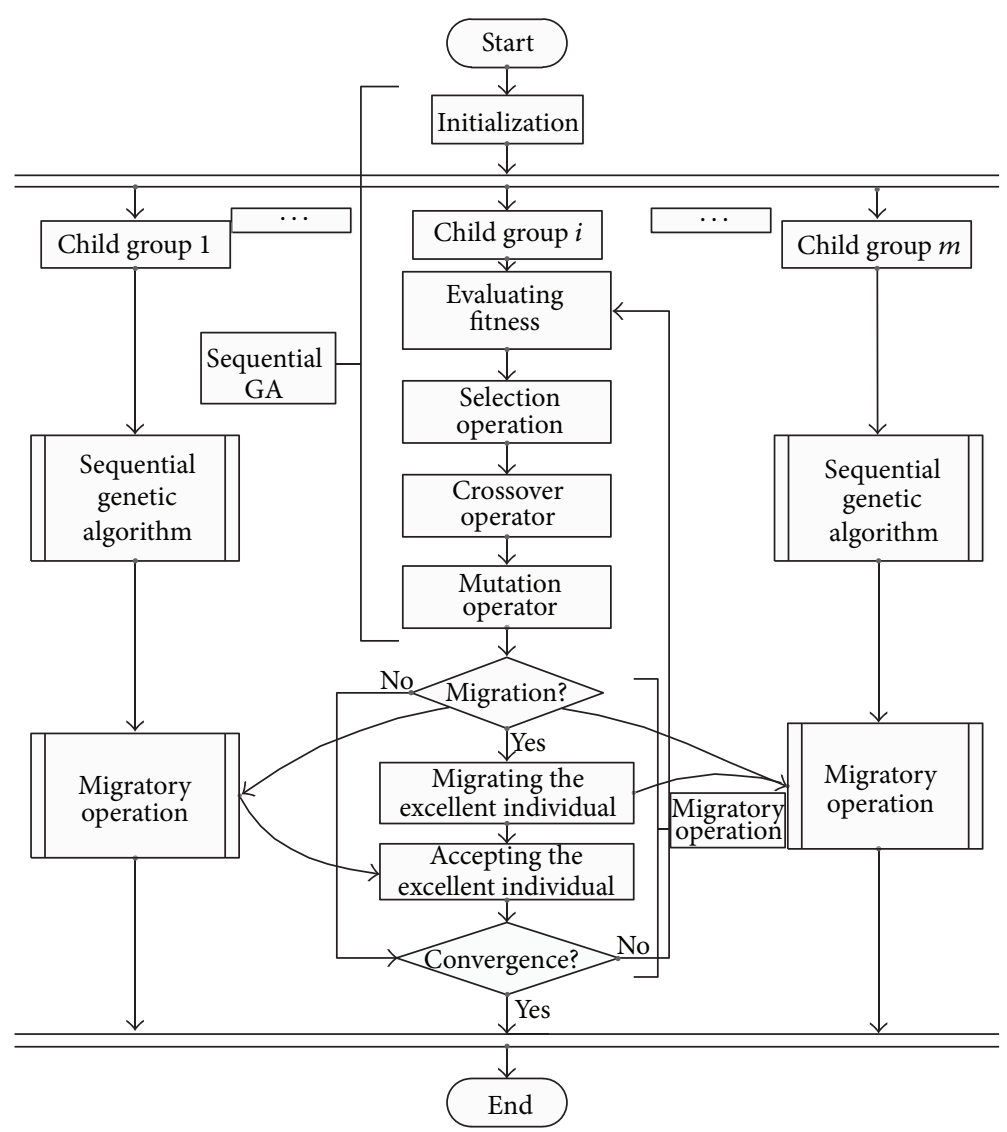

FIGURE 1: Flow chart of coarse-grained parallel genetic algorithm.

all the differences are small and value of the population is closed to the global optimal target value if the individual similarity of the current population is less than the minimum. For increasing the diversity of population, the current population should accept an individual of other population with maximum similarity to the current one. On the other hand, when the individual similarity is bigger than the maximum, the differences between individuals are great, meaning that the individual is far from the global optimal value. So the individual can accept an optimal individual from other population to hasten convergence. This migration strategy could save the optimal individual of population directly to the next generation.

\section{SCE-UA Algorithm for Damage Identification of Pipe Structure}

3.1. Principle and Description of SCE-UA Algorithm. SCEUA algorithm is a global optimization algorithm, which integrates the advantages of random search algorithm simplex method, clustering analysis and biological evolution method, and so on. It can effectively deal with the objective function with rough reflecting surface, not sensitive area [21]. Moreover, the algorithm is not interfered from the local minimum point [22]. It combines the complex search technology based on the deterministic with the biological competition principle of evolution in nature, and its key point is CCE. In CCE algorithm, each compound vertex is potential parent and could be involved in the calculation of producing the next generation. In the process of building, the child compound is selected by random, which leads to the search in the feasible region more thorough.

3.2. Parallel Strategy. SCE-UA algorithm has high intrinsic parallelism. Its process conforms to the Master-Slave pattern, so it is paralleled easily without changing any structure. In Master-Slave pattern, Master process performs the operation including sample space, initialization, compound sorting, and other global mixing operations; Slave process does the evolutionary operation. The figure of SCE-UA algorithm based on the Master-Slave is as in Figure 2.

First, the Master program performs the initialization operation, inputs the data of the model, and generates $s$ samples randomly in the sample space. Then, the samples are sorted according to the new objective function. Finally, the compound types divided are delivered to the Slave process. If the number of processor $n>p$, a processor is assigned to process a Slave; otherwise, a processor will be assigned to process more than a Slave. After that, a Slave process will be divided to some child compound types that generates next generation. When the evolutionary operation is completed, slave process will transfer the results to Master process for performing the mixing process. Then, the above processes are performed continuously, until the results are converged. 


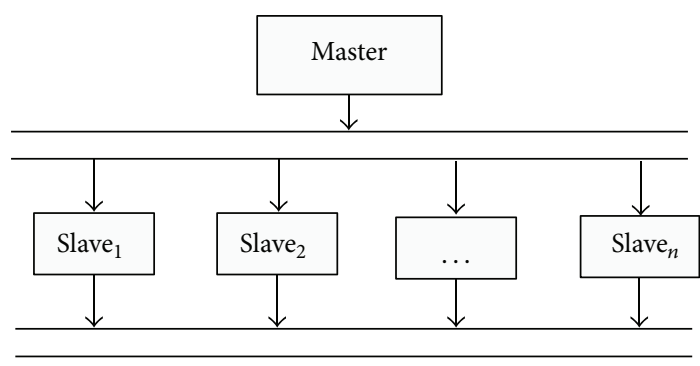

FIGURE 2: Parallel SCE-UA algorithm based on Master-Slave strategies.

\section{Applying GA and SCE-UA Algorithm for Damage Identification of Pipe Structure}

4.1. Input Parameters of the Algorithms. GA and SCE-UA algorithm must constitute an objective function when they are applied to damage identification of pipe structure. At present, the structural modal parameters are widely adopted (vibration mode and frequency), but strain modal can achieve high accuracy [8], so this paper chooses strain modal as input parameter.

Displacement modal calculated by finite element could be transferred to strain modal which is very accurate. The objective function of GA and SCE-UA algorithm is the difference value of strain modal between the intact and damage structure.

4.2. Damage Degree Identification and Evaluation of Pipe Structure. Generally, damage could reduce structural stiffness. Then, assuming that there are $R$ variables, the descripiton of structural damage follows:

$$
\alpha_{i} \in(0,1), \quad i=1 \sim R,
$$

where $\alpha_{i}$ is the damage degree of cell $i$, so stiffness matrix of cell $i$ is shown as (4)

$$
K_{e i}^{d}=\alpha_{i} K_{e i}^{0}
$$

where $K_{e i}^{0}$ stands for a stiffness matrix generated in an undamaged condition and $K_{e i}^{d}$ stands for a stiffness matrix generated in a damaged condition. Then, global stiffness matrix in damaged condition is as follows:

$$
K^{d}\left(\alpha_{1}, \alpha_{2}, \ldots, \alpha_{R}\right)=\sum_{i=1}^{R} K_{e i}^{d} .
$$

This paper calculated the strain modal in $N$ different damage cases, collected $M$ displacement data in each working condition, and obtained the corresponding strain modal. $u_{i j}^{a}$ denotes the strain modal $j$ under damage case $i ; u_{i j}^{m}$ means corresponding strain modal in undamaged condition. By adjusting damage variable $\alpha_{i}(i=1 \sim R), u_{i j}^{a}$ will be approached to $u_{i j}^{m}$ :

$$
\min \sum_{i=1}^{N} \sum_{j=1}^{M}\left|u_{i j}^{m}-u_{i j}^{a}\right|, \quad 0<\alpha_{i}<1 .
$$

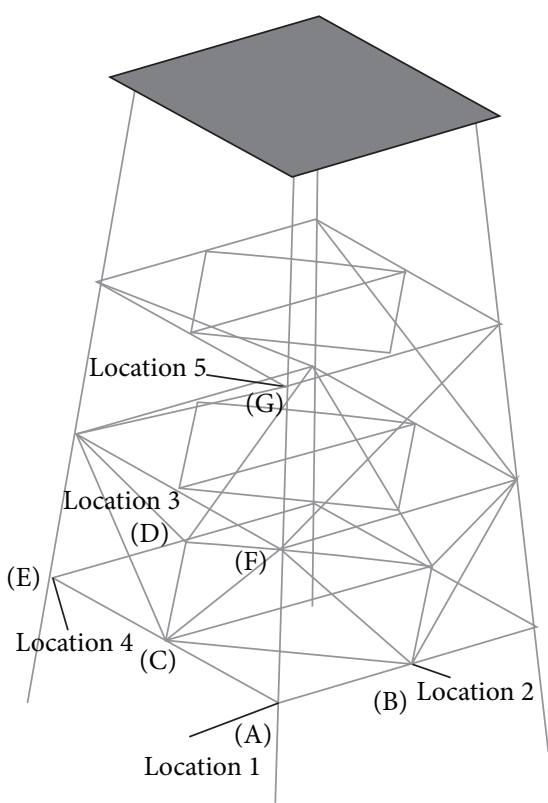

FIGURE 3: The structure of jacket offshore platform.

TABLE 1: The list of damage cases.

\begin{tabular}{lc}
\hline The label of damage cases & Damage degree (\%) \\
\hline 1 & 10 \\
2 & 20 \\
3 & 30 \\
4 & 40 \\
\hline
\end{tabular}

Thus, the problem is transferred to the mentioned objective function (5). As a result, GA and SCE-UA algorithm with powerful searching ability are applied for structural damage identification.

\section{Case Studies}

There is a jacket offshore platform, which can be seen in Figure 3. The platform is made of Q235 steel pipe. There are seven points selected for damage identification, which are noted as A, B, C, D, E, F, and G. Their locations can be seen in Figure 3. This paper considered five locations under 4 different damage cases. Damage cases are shown in Table 1.

(1) Location 1: damage is in Point A at Platform jacket leg.

(2) Location 2: damage is in Point B at horizontal pipe BC.

(3) Location 3: damage is in Point D at inclined pipe DG.

(4) Location 4: damage is in Point $\mathrm{C}$ at horizontal pipe AE.

(5) Location 5: damage is in Point G of the second layer jacket FG.

5.1. Damage Identification of Horizontal Pipe Structure. GA and SCE-UA algorithm are used to identify the structural 
TABle 2: The damage degree table of Point $\mathrm{A}$ at platform jacket leg in genetic algorithm.

\begin{tabular}{|c|c|c|c|}
\hline Cell number & $1-304$ & 305 & $306-21600$ \\
\hline \multicolumn{4}{|l|}{ Case 1} \\
\hline Design value of damage degree & 0.000 & 0.100 & 0.000 \\
\hline Identification value of damage degree & 0.000 & 0.098 & 0.000 \\
\hline \multicolumn{4}{|l|}{ Case 2} \\
\hline Design value of damage degree & 0.000 & 0.200 & 0.000 \\
\hline Identification value of damage degree & 0.000 & 0.187 & 0.000 \\
\hline \multicolumn{4}{|l|}{ Case 3} \\
\hline Design value of damage degree & 0.000 & 0.300 & 0.000 \\
\hline Identification value of damage degree & 0.000 & 0.291 & 0.000 \\
\hline \multicolumn{4}{|l|}{ Case 4} \\
\hline Design value of damage degree & 0.000 & 0.400 & 0.000 \\
\hline Identification value of damage degree & 0.000 & 0.383 & 0.000 \\
\hline
\end{tabular}

TABLE 3: The damage degree table of Point A at platform jacket leg in SCE-UA algorithm.

\begin{tabular}{|c|c|c|c|}
\hline Cell number & $1-304$ & 305 & $306-21600$ \\
\hline \multicolumn{4}{|l|}{ Case 1} \\
\hline Design value of damage degree & 0.000 & 0.100 & 0.000 \\
\hline Identification value of damage degree & 0.000 & 0.098 & 0.000 \\
\hline \multicolumn{4}{|l|}{ Case 2} \\
\hline Design value of damage degree & 0.000 & 0.200 & 0.000 \\
\hline Identification value of damage degree & 0.000 & 0.189 & 0.000 \\
\hline \multicolumn{4}{|l|}{ Case 3} \\
\hline Design value of damage degree & 0.000 & 0.300 & 0.000 \\
\hline Identification value of damage degree & 0.000 & 0.293 & 0.000 \\
\hline \multicolumn{4}{|l|}{ Case 4} \\
\hline Design value of damage degree & 0.000 & 0.400 & 0.000 \\
\hline Identification value of damage degree & 0.000 & 0.391 & 0.000 \\
\hline
\end{tabular}

TABLE 4: The damage degree table of Point B at horizontal pipe BC in genetic algorithm.

\begin{tabular}{|c|c|c|c|}
\hline Cell number & $1-8754$ & 8755 & $8756-21600$ \\
\hline \multicolumn{4}{|l|}{ Case 1} \\
\hline Design value of damage degree & 0.000 & 0.100 & 0.000 \\
\hline Identification value of damage degree & 0.000 & 0.089 & 0.000 \\
\hline \multicolumn{4}{|l|}{ Case 2} \\
\hline Design value of damage degree & 0.000 & 0.200 & 0.000 \\
\hline Identification value of damage degree & 0.000 & 0.191 & 0.000 \\
\hline \multicolumn{4}{|l|}{ Case 3} \\
\hline Design value of damage degree & 0.000 & 0.300 & 0.000 \\
\hline Identification value of damage degree & 0.000 & 0.271 & 0.000 \\
\hline \multicolumn{4}{|l|}{ Case 4} \\
\hline Design value of damage degree & 0.000 & 0.400 & 0.000 \\
\hline Identification value of damage degree & 0.000 & 0.387 & 0.000 \\
\hline
\end{tabular}

damage of spud leg FG, horizontal pipe AE, and inclined pipe BC. Strain modal data were input to GA and SCE-UA algorithm, the number of groups is 50 , and the iterations are 1000. Specific damage degree of two methods is shown as in Tables 2 and 3.

5.2. Analysis of Results. It is indicated that both GA and SCEUA algorithm have accurate identification results from Tables $3,4,5,6,7,8,9,10$, and 11. Although some identification values are not the same as the design values, the errors are very small. By comparing the two algorithms in Table 12, it is found that the results of SCE-UA are more exact. SCE-UA algorithm obtained better identification accuracy than GA did, which proves that SCE-UA is a powerful approach for damage identification of signal crack.

5.3. Comparison of Algorithms. The parameters of this paper are shown as in Table 13, and we compared the evolution results of two algorithms as in Figure 4. 
TABle 5: The damage degree table of Point B at horizontal pipe BC in SCE-UA algorithm.

\begin{tabular}{|c|c|c|c|}
\hline Cell number & $1-8754$ & 8755 & $8756-21600$ \\
\hline \multicolumn{4}{|l|}{ Case 1} \\
\hline Design value of damage degree & 0.000 & 0.100 & 0.000 \\
\hline Identification value of damage degree & 0.000 & 0.091 & 0.000 \\
\hline \multicolumn{4}{|l|}{ Case 2} \\
\hline Design value of damage degree & 0.000 & 0.200 & 0.000 \\
\hline Identification value of damage degree & 0.000 & 0.193 & 0.000 \\
\hline \multicolumn{4}{|l|}{ Case 3} \\
\hline Design value of damage degree & 0.000 & 0.300 & 0.000 \\
\hline Identification value of damage degree & 0.000 & 0.284 & 0.000 \\
\hline \multicolumn{4}{|l|}{ Case 4} \\
\hline Design value of damage degree & 0.000 & 0.400 & 0.000 \\
\hline Identification value of damage degree & 0.000 & 0.393 & 0.000 \\
\hline
\end{tabular}

TABle 6: The degree damage table of Point D at inclined pipe DG in genetic algorithm.

\begin{tabular}{|c|c|c|c|}
\hline Cell number & $1-15$ & 16 & $17-3300$ \\
\hline \multicolumn{4}{|l|}{ Case 1} \\
\hline Design value of damage degree & 0.000 & 0.100 & 0.000 \\
\hline Identification value of damage degree & 0.000 & 0.092 & 0.000 \\
\hline \multicolumn{4}{|l|}{ Case 2} \\
\hline Design value of damage degree & 0.000 & 0.200 & 0.000 \\
\hline Identification value of damage degree & 0.000 & 0.189 & 0.000 \\
\hline \multicolumn{4}{|l|}{ Case 3} \\
\hline Design value of damage degree & 0.000 & 0.300 & 0.000 \\
\hline Identification value of damage degree & 0.000 & 0.281 & 0.000 \\
\hline \multicolumn{4}{|l|}{ Case 4} \\
\hline Design value of damage degree & 0.000 & 0.400 & 0.000 \\
\hline Identification value of damage degree & 0.000 & 0.387 & 0.000 \\
\hline
\end{tabular}

TABLE 7: The damage degree table of Point D at inclined pipe DG in SCE-UA algorithm.

\begin{tabular}{|c|c|c|c|}
\hline Cell number & $1-15$ & 16 & $17-3300$ \\
\hline \multicolumn{4}{|l|}{ Case 1} \\
\hline Design value of damage degree & 0.000 & 0.100 & 0.000 \\
\hline Identification value of damage degree & 0.000 & 0.097 & 0.000 \\
\hline \multicolumn{4}{|l|}{ Case 2} \\
\hline Design value of damage degree & 0.000 & 0.200 & 0.000 \\
\hline Identification value of damage degree & 0.000 & 0.192 & 0.000 \\
\hline \multicolumn{4}{|l|}{ Case 3} \\
\hline Design value of damage degree & 0.000 & 0.300 & 0.000 \\
\hline Identification value of damage degree & 0.000 & 0.286 & 0.000 \\
\hline \multicolumn{4}{|l|}{ Case 4} \\
\hline Design value of damage degree & 0.000 & 0.400 & 0.000 \\
\hline Identification value of damage degree & 0.000 & 0.392 & 0.000 \\
\hline
\end{tabular}

We can find that operation time of SCE-UA algorithm is less under the same population size and evolutional generation. Although two algorithms almost did not change afterwards, SCE-UA has better convergence and higher robustness [23]. The fitness of SCE-UA did not change after 800th.
The fitness of GA increased rapidly before 500th generation, but it changed smoothly after 500th generation. GA had good convergence rate only in the initial stage of evolution, but when the distance is close to the optimal solution, GA was unable to search the optimal solution of this area quickly. 
TABLE 8: The damage degree table of Point $\mathrm{C}$ at horizontal pipe $\mathrm{AE}$ in genetic algorithm.

\begin{tabular}{|c|c|c|c|}
\hline Cell number & $1-26695$ & 26696 & $26697-56400$ \\
\hline \multicolumn{4}{|l|}{ Case 1} \\
\hline Design value of damage degree & 0.000 & 0.100 & 0.000 \\
\hline Identification value of damage degree & 0.000 & 0.086 & 0.000 \\
\hline \multicolumn{4}{|l|}{ Case 2} \\
\hline Design value of damage degree & 0.000 & 0.200 & 0.000 \\
\hline Identification value of damage degree & 0.000 & 0.191 & 0.000 \\
\hline \multicolumn{4}{|l|}{ Case 3} \\
\hline Design value of damage degree & 0.000 & 0.300 & 0.000 \\
\hline Identification value of damage degree & 0.000 & 0.286 & 0.000 \\
\hline \multicolumn{4}{|l|}{ Case 4} \\
\hline Design value of damage degree & 0.000 & 0.400 & 0.000 \\
\hline Identification value of damage degree & 0.000 & 0.391 & 0.000 \\
\hline
\end{tabular}

TABLE 9: The damage degree table of Point $\mathrm{C}$ at horizontal pipe AE in SCE-UA algorithm.

\begin{tabular}{|c|c|c|c|}
\hline Cell number & $1-26695$ & 26696 & $26697-56400$ \\
\hline \multicolumn{4}{|l|}{ Case 1} \\
\hline Design value of damage degree & 0.000 & 0.100 & 0.000 \\
\hline Identification value of damage degree & 0.000 & 0.093 & 0.000 \\
\hline \multicolumn{4}{|l|}{ Case 2} \\
\hline Design value of damage degree & 0.000 & 0.200 & 0.000 \\
\hline Identification value of damage degree & 0.000 & 0.192 & 0.000 \\
\hline \multicolumn{4}{|l|}{ Case 3} \\
\hline Design value of damage degree & 0.000 & 0.300 & 0.000 \\
\hline Identification value of damage degree & 0.000 & 0.286 & 0.000 \\
\hline \multicolumn{4}{|l|}{ Case 4} \\
\hline Design value of damage degree & 0.000 & 0.400 & 0.000 \\
\hline Identification value of damage degree & 0.000 & 0.394 & 0.000 \\
\hline
\end{tabular}

TABLE 10: The damage degree table of Point G of the second layer jacket FG in genetic algorithm.

\begin{tabular}{|c|c|c|c|}
\hline Cell number & $1-22004$ & 22005 & $22006-56400$ \\
\hline \multicolumn{4}{|l|}{ Case 1} \\
\hline Design value of damage degree & 0.000 & 0.100 & 0.000 \\
\hline Identification value of damage degree & 0.000 & 0.083 & 0.000 \\
\hline \multicolumn{4}{|l|}{ Case 2} \\
\hline Design value of damage degree & 0.000 & 0.200 & 0.000 \\
\hline Identification value of damage degree & 0.000 & 0.197 & 0.000 \\
\hline \multicolumn{4}{|l|}{ Case 3} \\
\hline Design value of damage degree & 0.000 & 0.300 & 0.000 \\
\hline Identification value of damage degree & 0.000 & 0.274 & 0.000 \\
\hline \multicolumn{4}{|l|}{ Case 4} \\
\hline Design value of damage degree & 0.000 & 0.400 & 0.000 \\
\hline Identification value of damage degree & 0.000 & 0.388 & 0.000 \\
\hline
\end{tabular}

\section{Conclusions}

Pipe structure of offshore platform is very huge, which was suffered by a variety of environmental factors. Thus, the jacket offshore platform was often caused with crack. It is an important task to identify the structural damage of pipe. However, it is difficult to detect the crack due to its unknown location. Thus, the damage identification problem is a largescale complicated problem. Heuristic algorithm is often a first choice to solve this kind of complicated problem. This paper firstly overviewed the basic theory of GA and SCE-UA algorithm and expounded the flow of the two algorithms. The process of applying GA and SCE-UA to identify the structural damage degree of platform is introduced. We selected strain 
TABle 11: The damage degree table of Point G of the second layer jacket FG in genetic algorithm.

\begin{tabular}{|c|c|c|c|}
\hline Cell number & $1-22004$ & 22005 & $22006-56400$ \\
\hline \multicolumn{4}{|l|}{ Case 1} \\
\hline Design value of damage degree & 0.000 & 0.100 & 0.000 \\
\hline Identification value of damage degree & 0.000 & 0.082 & 0.000 \\
\hline \multicolumn{4}{|l|}{ Case 2} \\
\hline Design value of damage degree & 0.000 & 0.200 & 0.000 \\
\hline Identification value of damage degree & 0.000 & 0.199 & 0.000 \\
\hline \multicolumn{4}{|l|}{ Case 3} \\
\hline Design value of damage degree & 0.000 & 0.300 & 0.000 \\
\hline Identification value of damage degree & 0.000 & 0.281 & 0.000 \\
\hline \multicolumn{4}{|l|}{ Case 4} \\
\hline Design value of damage degree & 0.000 & 0.400 & 0.000 \\
\hline Identification value of damage degree & 0.000 & 0.394 & 0.000 \\
\hline
\end{tabular}

TABLE 12: Damage determination analysis of the two methods.

\begin{tabular}{lccc}
\hline Type & Damage degree (\%) & Accuracy of GA & Accuracy of SCE-UA \\
\hline \multirow{3}{*}{ Single crack } & 10 & $100 \%$ & $100 \%$ \\
& 20 & $99.8 \%$ & $99.9 \%$ \\
& 30 & $100 \%$ & $100 \%$ \\
\hline
\end{tabular}

TABLe 13: Parameters in GA and SCE-UA.

\begin{tabular}{lccc}
\hline Algorithm & Population size & Evolutional generation & Computation time \\
\hline GA & 50 & 1000 & 293.7 \\
SCE-UA & 50 & 1000 & 231.2 \\
\hline
\end{tabular}

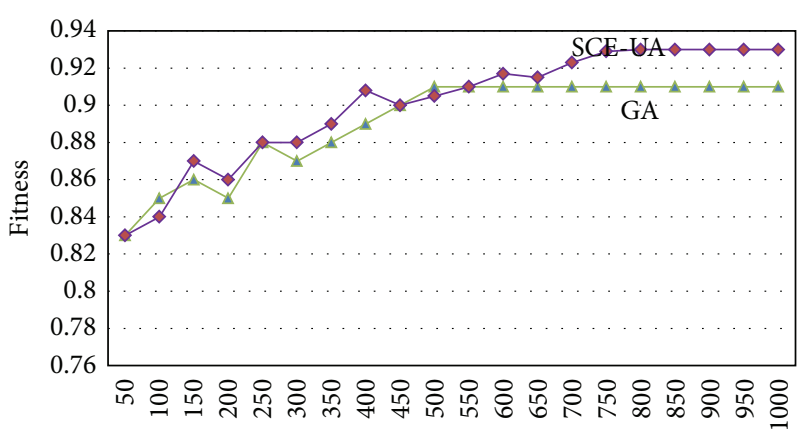

FIGURE 4: Fitness of each calculation.

modal difference as the input parameter owing to its accuracy and took 5 damages of a platform as an example to identify structural damage. The results showed that GA and SCEUA algorithm can achieve higher recognition accuracy and have good adaptabilities. The errors of SCE-UA algorithm are smaller, the computation time is less, and convergence is better. SCE-UA is a powerful tool for identifying structural damage of a platform pipe. In addition, the results also suggest that intelligent algorithm is a feasible method for structural damage identification.

\section{Acknowledgment}

The research is sponsored by the Major State Basic Research Development Program of China ("973" Program 2013CB036203), the Program for New Century Excellent Talents in the university (NCET-10-0219).

\section{References}

[1] B. Z. Yao, P. Hu, M. H. Zhang, and S. Wang, "Artificial bee colony algorithm with scanning strategy for the periodic vehicle routing problem," Simulation, vol. 89, no. 6, pp. 762-770, 2013.

[2] B. Z. Yao, C. Y. Yang, J. Hu, J. B. Yao, and J. Sun, "An improved ant colony optimization for flexible job shop scheduling problems," Advanced Science Letters, vol. 4, no. 6-7, pp. 2127-2131, 2011.

[3] B. Yu and Z. Z. Yang, "An ant colony optimization model: the period vehicle routing problem with time windows," Transportation Research Part E, vol. 47, no. 2, pp. 166-181, 2011.

[4] B. Yu, Z. Z. Yang, and B. Z. Yao, "An improved ant colony optimization for vehicle routing problem," European Journal of Operational Research, vol. 196, no. 1, pp. 171-176, 2009.

[5] B. Hillary and D. J. Ewins, "The use of strain gauges in force determination and frequency response function measurements," in Proceedings of the 2nd International Modal Analysis Conference (IMAC'84), pp. 627-634, Orlando, Fla, USA, 1984. 
[6] C. H. Staker, "Modal analysis efficiency improved via strain frequency response functions," in Proceedings of the 3rd International Modal Analysis Conference (IMAC '85), pp. 612-617, 1985.

[7] O. Bernasconi and D. J. Ewins, "Application of strain modal testing to real structures," in Proceedings of the 7th International Modal Analysis Conference(IMAC '89), pp. 1453-1464, Los Angeles, Calif, USA, 1989.

[8] L. H. Yam, T. P. Leung, D. B. Li, and K. Z. Xue, "Theoretical and experimental study of modal strain analysis," Journal of Sound and Vibration, vol. 191, no. 2, pp. 251-260, 1996.

[9] W. F. Tsang, "Use of dynamic strain measurements for the modeling of structures," in Proceedings of the 8th International Modal Analysis Conference (IMAC '90), pp. 1246-1251, 1990.

[10] J.-C. Hong, Y. Y. Kim, H. C. Lee, and Y. W. Lee, "Damage detection using the Lipschitz exponent estimated by the wavelet transform: applications to vibration modes of a beam," International Journal of Solids and Structures, vol. 39, no. 7, pp. 18031816, 2002.

[11] Y. C. Ren, S. C. Ma, and L. Lin, "Beam fracture identification under moving load of the wavelet study," Journal of Vibration and Shock, vol. 23, no. 2, pp. 82-85, 2004.

[12] P. H. Kirkegaard and A. Rytter, "The use of neural networks for damage detection and location in a steel member," in Neural Networks and Combinatorial Optimization in Civil and Structural Engineering, pp. 1-9, Civil-Comp, Edinburgh, UK, 1993.

[13] N. Mitsuru, S. F. Masrisami, A. G. Chassiakos, and T. K. Caughey, "A method for non-parametric damage detection through the use of neural networks," Earthquake Engineering and Structural Dynamics, vol. 27, no. 9, pp. 997-1010, 1998.

[14] R. Ruotolo and C. Surace, "Damage assessment of multiple cracked beams: numerical results and experimental validation," Journal of Sound and Vibration, vol. 206, no. 4, pp. 567-588, 1997.

[15] S. F. Masri, A. W. Smyth, A. G. Chassiakos, T. K. Caughey, and N. F. Hunter, "Application of neural networks for detection of changes in nonlinear systems," Journal of Engineering Mechanics, vol. 126, no. 7, pp. 666-676, 2000.

[16] D.-Y. Chiang and W.-Y. Lai, "Structural damage detection using the simulated evolution method," AIAA journal, vol. 37, no. 10, pp. 1331-1333, 1999.

[17] J.-H. Chou and J. Ghaboussi, "Genetic algorithm in structural damage detection," Computers and Structures, vol. 79, no. 14, pp. 1335-1353, 2001.

[18] J. W. Yi and X. Liu, "Structural damage detection based on genetic algorithm," Engineering Mechanics, vol. 18, no. 2, pp. 6471, 2001.

[19] J. S. Zhu and R. C. Xiao, "Large span cable-stayed bridge damage identification based on the regular testing and genetic algorithm," China Civil Engineering Journal, vol. 39, no. 5, pp. 85-89, 2006.

[20] T. Matsumura, M. Nakamura, J. Okech, and K. Onagat, "A parallel and distributed genetic algorithm on loosely-coupled multiprocessor systems," IEICE Transactions on Fundamentals of Electronics, Communications and Computer Sciences, vol. E81A, no. 4, pp. 540-546, 1998.

[21] Q. Y. Duan, V. K. Gupta, and S. Sorooshian, "Shuffled complex evolution approach for effective and efficient global minimization," Journal of Optimization Theory and Applications, vol. 76, no. 3, pp. 501-521, 1993.

[22] G. Kuczera, "Efficient subspace probabilistic parameter optimization for catchment models," Water Resources Research, vol. 33, no. 1, pp. 177-185, 1997.
[23] D. E. Goldberg, Genetic Algorithms in Search, Optimization and Machine Learning, Addison-Wesley, Reading, Mass, USA, 1st edition, 1989. 


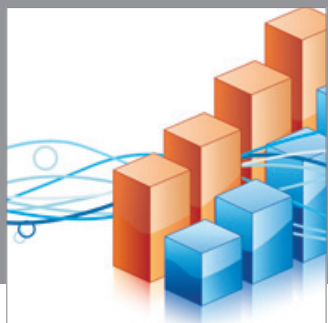

Advances in

Operations Research

mansans

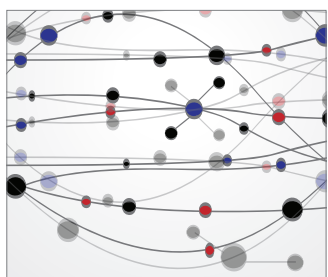

The Scientific World Journal
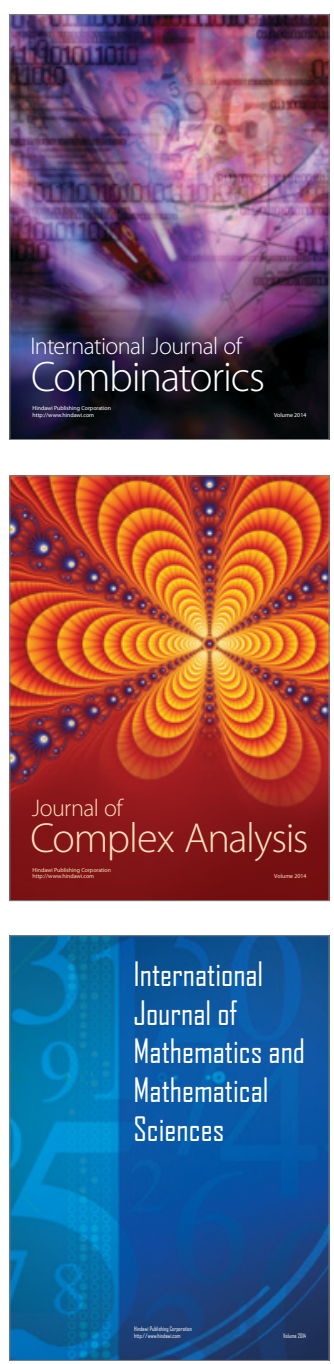
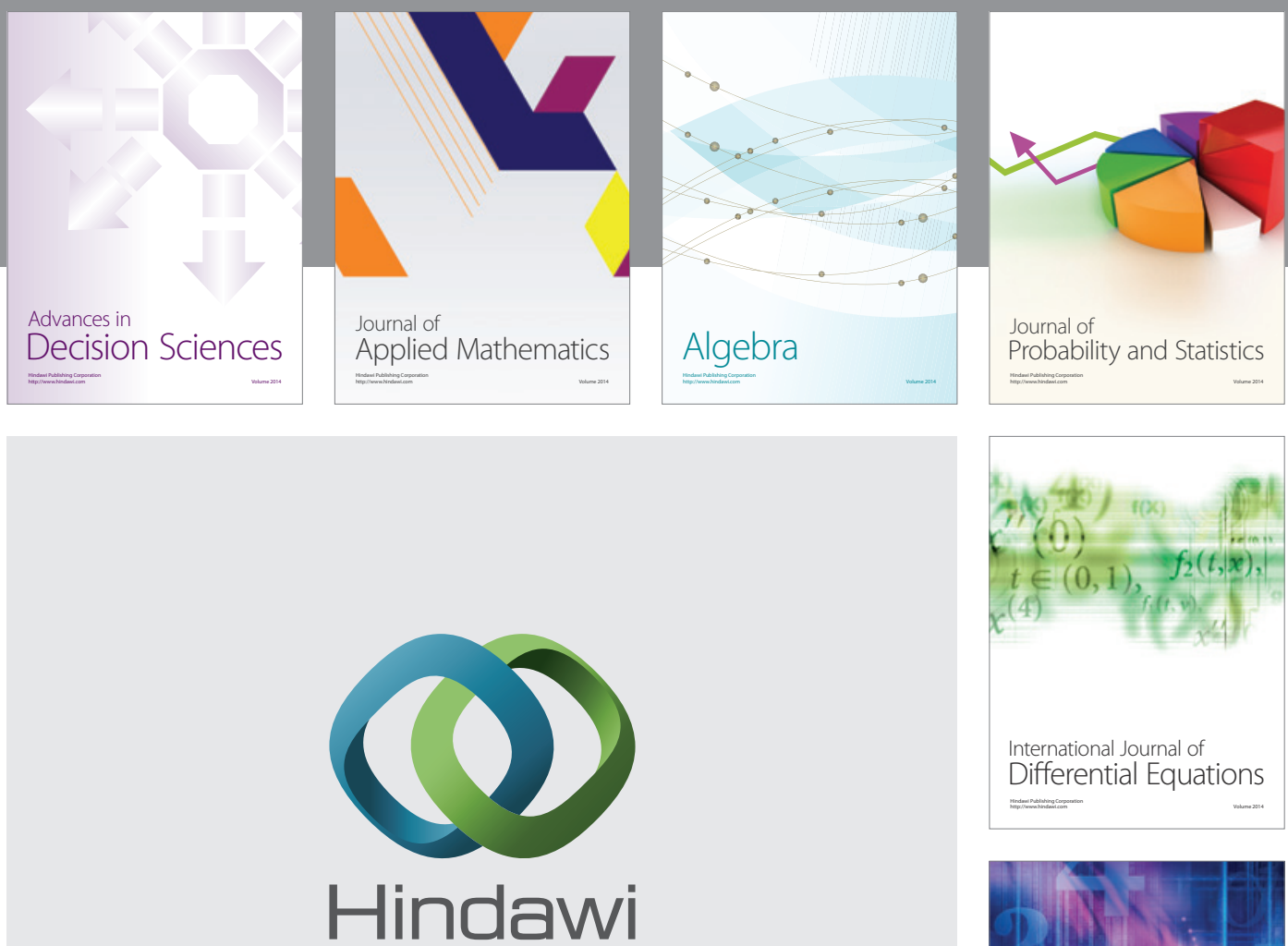

Submit your manuscripts at http://www.hindawi.com
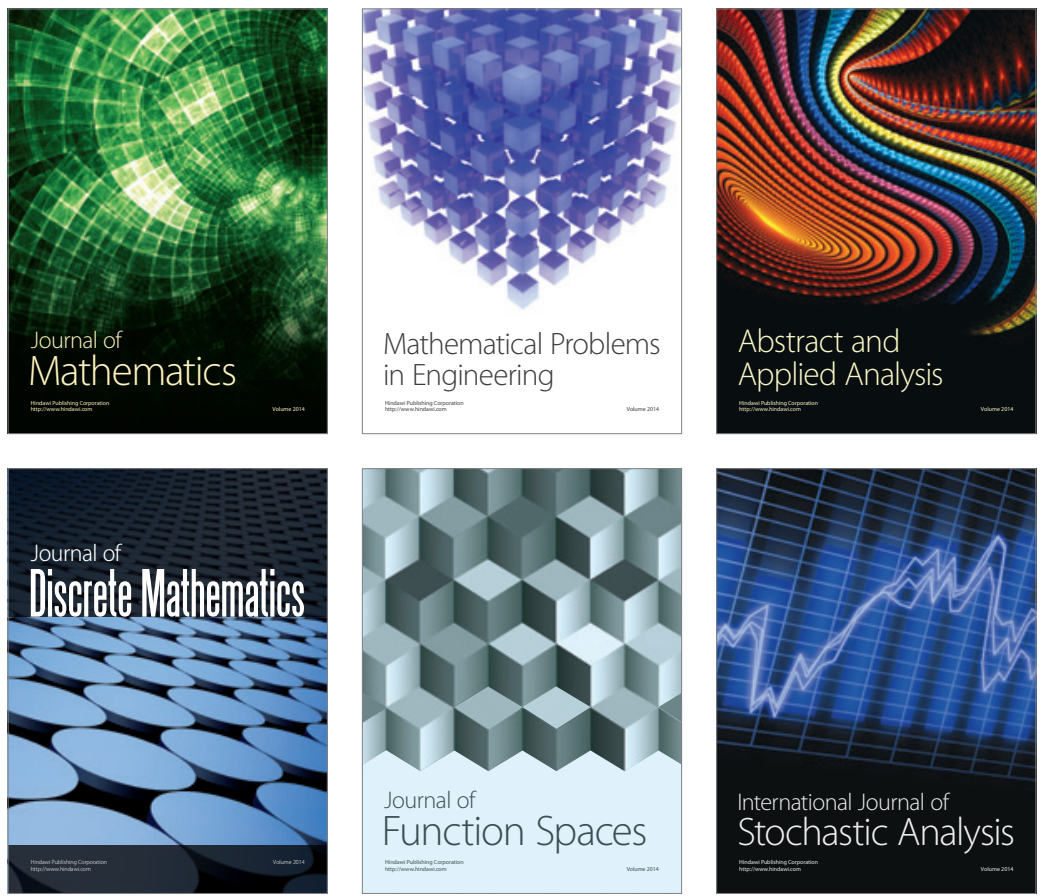

Journal of

Function Spaces

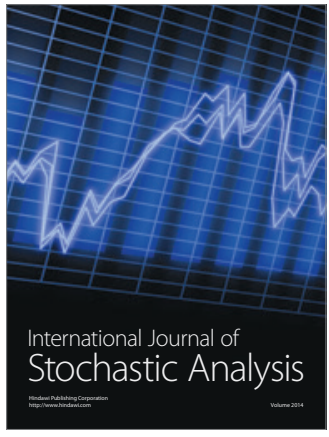

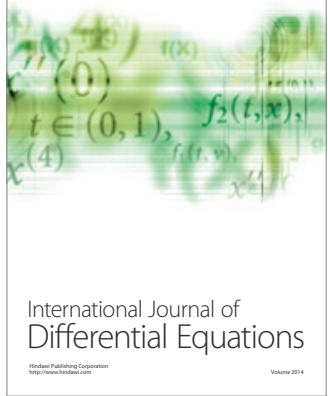
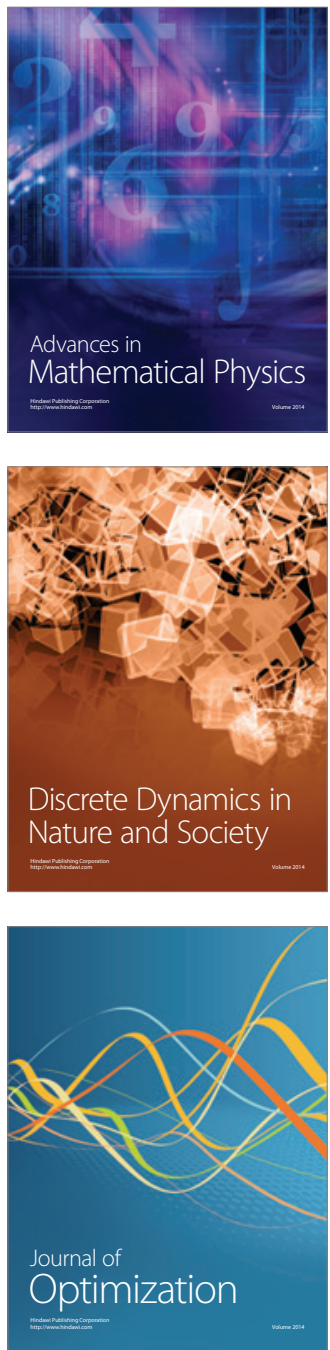